Arthur Imhof has remarked. But when humanists belittle the progress made in the past few centuries, I doubt that they would have us regress to such pre-Enlightenment conditions.

This book seems to emanate a feeling of suffering from modernity, while emphasizing that innovation will be the inevitable hallmark of modernity (or rather, postmodernity, as the dark alley ahead of modernity will always have to be called). As the Roman historian Titus Livius succinctly put it more than 2,000 years ago, "Nec vitia nostra nec remedia pati possumus" ("We can endure neither our vices nor their remedies"), which shows that this ambivalence is not so recent.

There are a few minor points to be raised. First, it seems regrettable that this essay from a leading European science-policy figure has not been published in English. Maybe this is because the mixture of socio-scholarly, doubt- ridden, intellectual Zeitgeist and Menschenbild worries is only too German? It is to be hoped, however, that this is not the Menschenbild exemplified by the art of Patricia Piccinini on the cover of this book, which depicts a young family of pig-like humans or humanized pigs! If there is to be an English edition, hopefully minor errors, such as the claim that prokaryotes evolved from eukaryotes (it was the other way round), or the figures for derivative financial markets, which mix up US trillions and the German Trillionen, can be corrected.

Such minor quibbles aside, this is a very readable book. It is thought provoking, but also incited me to disagree with some of its doom-laden messages. Insatiable curiosity? Let's hope so, under the challenging demands of unending necessity.

Hubert S. Markl is in the Department of Biology,

University of Konstanz, 78457 Konstanz, Germany.

\title{
A climate for social change
}

\section{The Weather in the Imagination \\ by Lucian Boia \\ Reaktion: 2005. 224 pp. $€ 14.95$}

\section{Julian Hunt}

It's probably only fair that Nature should publicize the views of a historian about meteorology, because in the past it has published influential letters by meteorologists on history. Lewis Fry Richardson demonstrated that differential equations and statistical laws that can successfully model weather systems should also be able to model humans' behaviour and maybe even psychology, from their proclivity for conflict to their appreciation of jazz. This approach not only explains quantitatively how wars did or did not develop, but in 1935 and 1951 predicted future developments (see Nature 411, 737; 2001).

Lucian Boia, a historian at the University of Bucharest in Romania, has written a stimulating book, The Weather in the Imagination, reviewing the literature on theories of how climate has affected societies, and of how humans may have influenced climate. He concludes with a personal, if not entirely accurate, account of the science of human-induced climate change, and debates the current policy options. He reveals his methodological bias, however, when he implies that Newton's work on predicting the movement of planets is a rather simple matter compared with studying the complexity of history. (Richardson, in contrast, had noted that, like the natural world, societies can in some respects have simple mathematical descriptions, for example in the way that armaments can grow exponentially before a war, and that the frequency of conflicts tends to follow a Poisson distribution.)

The big historical question in this book - the extent to which national characteristics are determined by the weather and climate - has been addressed in fascinatingly different ways by Hippocrates, historian Edward Gibbon, French philosopher Montesquieu, the Arab historian Ibn Khaldun, and more recently by Hubert Lamb and Emmanuel Le Roy Ladurie. Much of the evidence is anecdotal and rather surprising. The Greeks thought that the cold weather made the British not only aggressive but sexually promiscuous - obviously the directors of recent reality TV shows could have saved themselves a lot of money by staying in Britain, if only they had read their Hippocrates. Gibbon extended this climate hypothesis by arguing that people from northern Europe had also been influenced by the way they modified their climate through deforestation and agriculture. Some writers included real weather observations: the Venerable Bede in the eighth century included in his chronicle a now well known statistical forecast: "Red sky at night is a shepherd's delight." Montesquieu, in contrast, studied the taste buds of sheep's tongues and their blood circulation at various temperatures, and concluded that northern people were bold and not very devious or sensitive compared with those from lower latitudes!

This kind of thinking and eccentric collection of data continued until the early twentieth century when geographers, historians and anthropologists pointed out that societies evolve as much through organization and religion, for example, as through climate.

Boia brings a topical dimension to his perspective when he emphasizes the relation between the way societies have dealt with climatic events and with natural disasters. In their reactions to the sudden loss of life and disruption associated with the latter, most societies have sought religious explanation. The Bible and other early writings focused on whirlwinds, fire, earthquakes, floods and droughts. They also revealed how various kinds of 'divine intervention' have helped or hindered the hazard, depending on the point of view: the Japanese, for example, are grateful for the 'kamikaze' typhoon that saved them from Genghis Khan. The ice age was the last globally significant climate change that humans endured. It was also a natural disaster of huge proportions as the ice retreated some 10,000 years ago. This shaped the landscape of Britain and was probably associated with floods in the Middle East, India and the northwestern United States (where the mythical raven god carried people away on its wings).

This extreme form of climate change was feared by religious alarmists to be imminent at the start of the sixteenth century. This led the president of the Toulouse parliament in France to use the famous woodworking skills of the region to build another ark. According to the Michelin guide, these skills later led to the Lagardère media company and Airbus.

In the concluding chapter on climate change, Boia sides with Bjørn Lomborg in suggesting that a $2{ }^{\circ} \mathrm{C}$ change in global temperature is

IMAGE

UNAVAILABLE FOR COPYRIGHT REASONS

More sex please, we're British: did the climate, painted here by Constable, make people promiscuous? 
of no great concern. A conference of meteorologists held in Exeter, UK, in February (www.stabilisation2005.com) disagreed, concluding that such an outcome would be unacceptable to most societies if they had a choice in the matter. Boia himself points out that such a rise in temperature will lead to the loss of mountain glaciers and the destruction of millions of species of plants and animals. He makes a technical error, however, in stating that the reduction of emissions needed to mitigate this rise can be provided solely by the more economical and efficient use of transport. These steps, although necessary, are insufficient: the excessive use of energy for heating and cooling buildings, which in most countries gives rise to $50 \%$ of emissions, also needs to be curbed.

Lomborg is correct that the local environment and living standards are improving for many people. But some climate models would see people reduced to communities perched on hilltops in a depleted natural environment. Some of us might be living on the water in the next generation of ark, indeed the Netherlands is planning to develop floating houses for use in the most flood-prone areas of the country.

An alternative reading of history might conclude that human societies can rise to extraordinary challenges, as the 3,000-year-old society of China surely demonstrates, and should therefore be able to avert the climatic consequences of our actions and prevent their worst effects. Unfortunately that is not the message of this important book.

Julian Hunt is in the Centre for Polar Observation

and Modelling, Department of Space and

Climate Physics, University College London,

Gower Street, London WC1E 6BT, UK.

\section{Early views of viewing}

\section{The Moving Tablet of the Eye: The Origins of Modern Eye Movement Research by Nicholas J. Wade \& Benjamin W. Tatler Oxford University Press: 2005. 312 pp. €75, \$145 (hbk); £29,95 (pbk)}

\section{John M. Findlay}

"Why is it to those who are very drunk everything appears to revolve?" Nicholas Wade and Benjamin Tatler use this question, once posed by Aristotle, to illustrate visual vertigo, the illusory motion of the visual world. A further challenging question is why, during our more sober moments, do we not have such experiences, and instead perceive a stable world, despite the continual changes of retinal stimulation resulting from the motion of our eyes.

Since at least the time of Johannes Kepler, some 400 years ago, research in vision has been based on the image-forming eye. The apparent close correspondence between our perceptual experience and our retinal image has generally led to the second question being answered in terms of the 'suppression' of, and 'compensation' for, the changes caused by the eyes' motion. Yet these terms, particularly the latter, presuppose some form of 'inner screen' representation. As the authors point out, the intuitively appealing idea of a detailed mental copy of our visual environment is increasingly recognized as a 'grand illusion'. Some researchers, notably J. Kevin O’Regan and Alva Noë, even reject any form of internalized visual representation. In line with this reappraisal there has been more appreciation of the importance of the mobility of the eyes in visual science; Wade and Tatler at one point contend that "eye movements lie at the heart of contemporary studies of vision".

The Moving Tablet of the Eye is a chronicle of the history, reinterpreted by modern thinking, of studies of seeing actively and of the many contributions to the field from the ancient Greeks to the early twentieth century. One of its idiosyncrasies is the predilection for providing physiognomic rather than geographic information about the scientists involved. The book contains more than sixty miniature

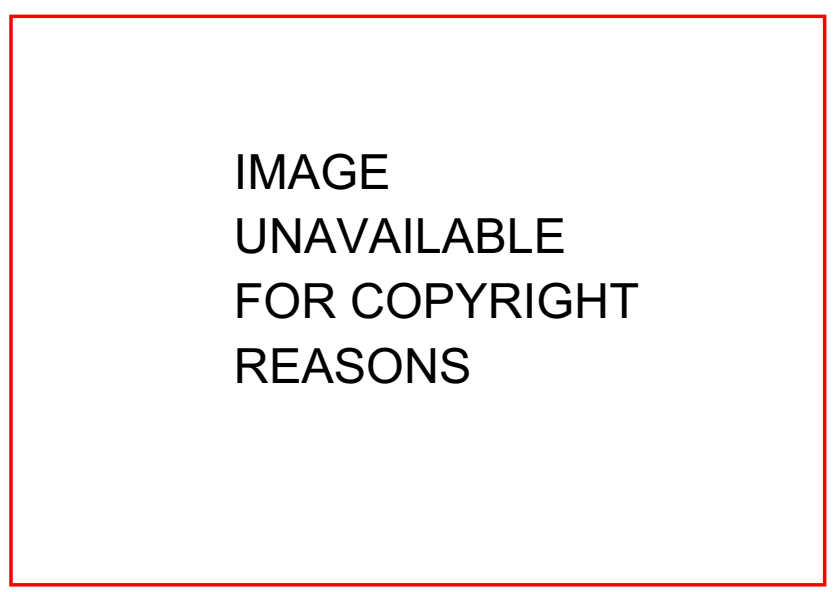

We normally perceive a stable world even though our eyes keep moving.

portraits, but biographic information other than dates is provided only for the major players, such as William Porterfield, Charles Wells, Émile Javal and Raymond Dodge.

The first two names highlight the advanced level of intellectual activity in Scotland in the eighteenth and early nineteenth centuries. Porterfield, an Edinburgh physician, certainly appreciated the importance of eye movements. In a publication in 1737 he decried the "Vulgar Error" of assuming that we see everything distinctly, clearly and at the same time. Wells, who was educated in Scotland but worked in London, demonstrated (using extended vestibular stimulation, rather than inebriation) that visual vertigo is linked to eye motion. His use in the 1790s of after-images for this purpose anticipated the major technique used to study eye movements during the following century. Wells successfully defended his position against a challenge from the august figure of Erasmus Darwin, whose integration of speculative science and ponderous poetry is well represented in the book and provided the inspiration for the title.

Another notable piece of historical research by the authors reveals the initial use of the term 'saccade' and the first appreciation of the jerky quality of eye scanning. Javal, a distinguished French ophthalmologist, is now often credited with both, thanks to a careless attribution in Edmund Huey's classic text on reading. The term saccade was first used in an oculomotor context in Javal's writings in 1879 , but in a footnote describing an observation by A. Lamare, a co-worker in Javal's laboratory at the Sorbonne. Using a mechano-acoustic transducer, Lamare heard noises corresponding to the discontinuous movements of the eyes during reading, and observed that the number of saccades per line of text is unchanged, regardless of the viewing distance. However, he didn't get round to publishing until 1892. In fact, no less a figure than Ewald Hering carried out a similar experiment, correlated the resultant "dull clapping" sounds with after-image movements, and published the finding, also in 1879.

This book is extensive and thorough but not exhaustive. The history largely stops in the early years of the twentieth century, so the near absence of any oculomotor neuroscience is justifiable - although the fascinating neurological condition of 'psychic paralysis of gaze' might have merited a mention. Another surprising omission is the work of E. E. Maddox on the preconditions for vergence movement. The authors have made every effort to integrate the study of looking with that of seeing, but the malign influence of the grand illusion can perhaps still be detected when we read that the saccade-and-fixate strategy "evolved as an adaptation to the demands of a highly mobile eye". But these are minor blemishes on a fascinating work and a splendid scholarly achievement. The book will surely stand as the definitive text on the history of eye-movement research for many years to come. John M. Findlay is in the Department of Psychology, University of Durham, South Road, Durham DH1 3LE, UK. 